\title{
A Study of Nitrite Oxidation at Platinum Microelectrodes
}

\author{
Mauro Bertotti*a, and Derek Pletcher ${ }^{b}$ \\ ${ }^{a}$ Instituto de Química, Universidade de São Paulo, 05508-900 São Paulo - SP, Brazil \\ ${ }^{b}$ Department of Chemistry, The University, Southampton SO17 1BJ, England
}

Received: October 25, 1996

\begin{abstract}
No presente trabalho são apresentados estudos envolvendo a oxidação eletroquímica de nitrito na superfície de microeletrodos de platina de raios compreendendo a faixa de 5 a $25 \mu \mathrm{m}$. Observou-se que o mecanismo da reação eletródica não se restringe a processo puramente difusional e que a resposta do eletrodo é largamente influenciada pela formação de óxidos de platina. Utilizando procedimento envolvendo pré-condicionamento do eletrodo em meio de $\mathrm{KCl}$ foi possível desenvolver um método amperométrico bastante simples para a determinação de nitrito com limite de detecção na faixa de $2 \mu \mathrm{M}$.
\end{abstract}

The anodic oxidation of nitrite at Pt microdisc electrodes (radii 5-25 $\mu \mathrm{m}$ ) has been studied. It is shown that the electrode reaction is not simple and the response is determined by the oxide coverage of the surface. It is, however, possible to define conditions for the amperometric determination of nitrite in neutral, aqueous chloride solutions; once the electrode surface is preconditioned, the method is rapid and simple and has a lowest detection limit of $\approx 2 \mu \mathrm{M}$.

Keywords: nitrite, microelectrodes, platinum oxide

\section{Introduction}

Nitrite and nitrate are important in the chemistry of the environment since both species play an important role in the analysis of natural waters and other environmental materials. This has led to many recent studies of analytical procedures for their determination. The search for simple and rapid methods of analysis of both ions has included the development of flow injection procedures, many of them coupled to ion chromatographic instruments. The detection of the analytes has been carried out both spectrophotometrically and electrochemically; the advantages of electrochemical detection are the rapid response and the avoidance of potentially unstable compounds produced in some of the colorimetric methods.

The cathodic behaviour of nitrate and nitrite is always similar. Both ions require highly acidic conditions for the reduction to take place, nitrogen, nitrous oxide and ammonia being the products of the electrolysis under some experimental conditions ${ }^{1}$. Analytical methods based on the reduction processes have always to consider sources of interference such as hydrogen evolution, justifying the use of mercury electrodes in catalytic polarographic or adsorptive cathodic stripping voltammetric methods ${ }^{2-4}$. However, in contrast to nitrate, nitrite may also be oxidised. Hence, several papers have described the anodic oxidation of nitrite at platinum ${ }^{5-7}$ and vitreous carbon ${ }^{8,9}$ and there has been a recognition that modification of the Pt surface improves the performance of the anode as a detector. On the other hand, there appears to have been no attempts to understand the mechanism of nitrite oxidation or the difficulties found with unmodified Pt surfaces. Therefore, in this paper we have investigated further the oxidation of nitrite on $\mathrm{Pt}$ microelectrodes $^{10-13}$.

The use of microelectrodes as an analytical tool for the determination of nitrite has already been reported ${ }^{14}$. On carbon and gold microfibres it was shown that good steady state voltammograms could be obtained by using the linear sweep voltammetry technique. The limiting currents of these voltammograms were proportional to the analyte concentration and the detection limits estimated suggested the use of the methodology for monitoring nitrite in natural waters.

The anodic oxidation of nitrite is known to occur at moderate potentials $(c a .1 .0 \mathrm{~V} v s$. SCE) at platinum electrodes, however difficulties associated with the surface passivation by platinum oxides restricts this approach as a method for the analyte determination. Accordingly, the method 
presented in this paper deals with the amperometric detection of nitrite on platinum surfaces. In this paper a careful treatment of the electrode surface is described and it will be shown that after such, platinum microelectrodes constitute a reliable sensor for the electrochemical detection of nitrite.

\section{Experimental}

\section{Instrumentation}

Platinum microelectrodes were fabricated by sealing microwires into glass, cutting perpendicular to the wire and polishing with emery paper and then with alumina powder $(1,0.3$ and $0.05 \mu \mathrm{m})$ on a polishing cloth. Their radii were checked by measuring the steady state current for ferricyanide solutions of known concentration and comparing to the equation that describes the steady state current for a microelectrode (Eq. 1). A small beaker was used as a cell, the reference electrode was a commercial SCE $(\mathrm{KCl})$. All electrochemical experiments were performed with a Hi-Tek waveform generator and the currents were amplified with a laboratory-built amplifier. No deoxygenation was necessary and all experiments were carried out at room temperature, $293 \pm 2 \mathrm{~K}$.

\section{Chemicals}

Solutions were prepared by dissolving the analytical grade reagents in Millipore water. Standard nitrite solutions (prepared with the $\mathrm{NaNO}_{2}$ salt) were standardised using a recommended procedure from the literature ${ }^{15}$.

\section{Results}

Figure 1 shows current (I) vs. potential (E) plots recorded at $10 \mathrm{mV} \mathrm{s}^{-1}$ for three freshly polished $\mathrm{Pt}$ microdisc electrodes in a solution of $1 \mathrm{mM} \mathrm{NO}_{2}^{-}$in $0.1 \mathrm{M} \mathrm{KCl}$ $(\mathrm{pH}=7)$. At the largest microdisc radius, $25 \mu \mathrm{m}$, the oxidation of nitrite leads to a well formed oxidation wave at $\mathrm{E}_{1 / 2}=+730 \mathrm{mV} v$ s. SCE and with $\mathrm{E}_{3 / 4}-\mathrm{E}_{1 / 4} \approx 50 \mathrm{mV}$. The limiting current plateau, however, does not extend over a wide potential range and positive to $+950 \mathrm{mV}$, the current decreases again. Moreover, in contrast to the expected behaviour at a microelectrode at slow scan rates ${ }^{10-13}$, it can be seen that the reverse scan shows considerable hysterisis; at all potentials the anodic current is significantly lower. Almost no hysterisis is observed if the scan is reversed at $+850 \mathrm{mV}$. The figure also shows that at the smaller microdiscs, these trends are exacerbated and, with a $5 \mu \mathrm{m}$ microdisc, it is more difficult to identify a significant plateau in the I - E response. On the other hand, when the "plateau currents" are plotted versus the disc radii, a linear plot is observed, see the inset to Fig. 1. This implies that under these conditions and at potentials in the range $850-900 \mathrm{mV}$, the oxidation of nitrite is mass transport

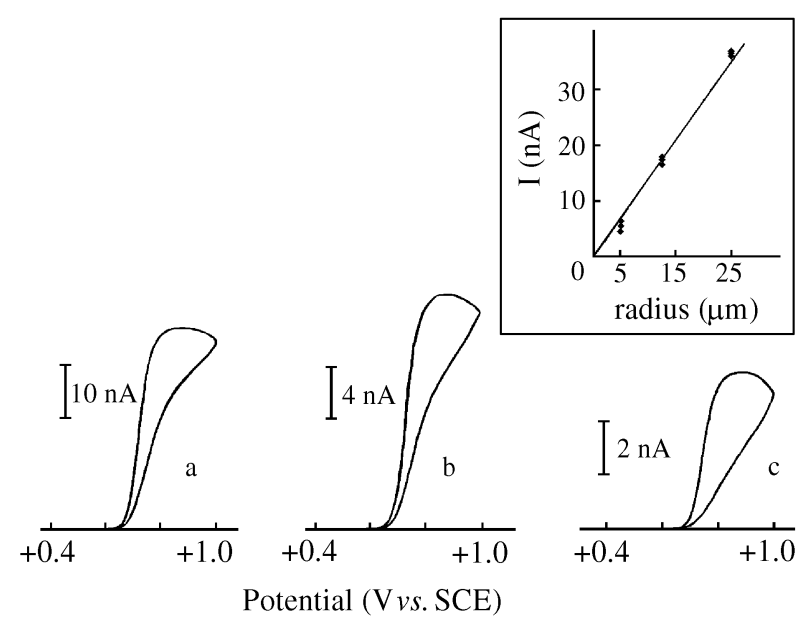

Figure 1. Cyclic voltammograms for freshly polished $\mathrm{Pt}$ microdisc electrodes in a solution containing $1 \mathrm{mM}$ nitrite and $0.1 \mathrm{M} \mathrm{KCl}(\mathrm{pH}=$ 7). Electrode radii are (a) $25 \mu \mathrm{m}$ (b) $12.5 \mu \mathrm{m}$ and (c) $5 \mu \mathrm{m}$. Potential scan rate $10 \mathrm{mV} \mathrm{s}^{-1}$. The inset shows the corresponding plot of $\mathrm{I}_{\mathrm{L}} \mathrm{vs} \mathrm{r}$ and the multiple points for each radius indicates the reproducibility of the experiments.

controlled. The mass transport limited current to a microdisc electrode is given by ${ }^{10-13}$

$$
\mathrm{I}_{\mathrm{L}}=4 \mathrm{nFDcr}
$$

where $\mathrm{n}$ is the number of electrons transferred in the electrochemical process (here $\mathrm{n}=2$ assuming that the final product of the anodic oxidation is nitrate), $\mathrm{F}$ is the Faraday constant, $\mathrm{D}$ is the diffusion coefficient of the electroactive species, $\mathrm{c}$ is the concentration and $\mathrm{r}$ is the radius of the microelectrode. Moreover, the slope of the linear plot leads to a value for the diffusion coefficient of nitrite which is $1.2 \times 10^{-5} \mathrm{~cm}^{2} \mathrm{~s}^{-1}$, close to that expected for a small anion in aqueous solution ${ }^{16}$ and in agreement with the value obtained by Silva et al. ${ }^{14}$ using data from a chronoamperometric experiment with a carbon fiber microelectrode in $0.05 \mathrm{M} \mathrm{Na}_{2} \mathrm{SO}_{4}$. The inset to Fig. 1 also shows the reproducibility of the "limiting currents" (for each radius, three experimental points are shown); with careful polishing of the microdiscs, the currents were reproducible to $\pm 5 \%$. Cyclic voltammograms at Pt electrodes, area $0.10 \mathrm{~cm}^{2}$, confirmed that the oxidation of nitrite is completely irreversible.

These results would suggest that the oxidation of nitrite at a Pt anode is mass transport controlled over a narrow range of potentials and on the timescale of these experiments. It is, however, clear from figure 1 that the current decreases as the potential is taken positive to $+900 \mathrm{mV}$ and it was also found that the current decayed if the potential was held at $+850 \mathrm{mV}$ for an extended period. Both these observations are compatible with the conclusion that platinum oxide formed on the anode surface inhibits nitrite oxidation. 
Figure 2 illustrates the influence of $\mathrm{pH}$ on the I - E plots for nitrite oxidation at a $\mathrm{Pt}$ microdisc electrode, radius $12.5 \mu \mathrm{m}$ in $0.1 \mathrm{M} \mathrm{KCl}$. Comparison of Figs. 2(a) and (b) demonstrates that even a small increase of the $\mathrm{pH}$ to 9 led to almost complete loss of the oxidation wave at $\mathrm{E}_{1 / 2}=$ $+730 \mathrm{mV}$. Since it seemed unlikely that the nitrite ion is unstable in this mildly alkaline solution, voltammograms were recorded over the same potential range for the electrolytes in the absence of nitrite. These voltammograms, recorded at a much higher current sensitivity than Figs. 2(a)-(c) are shown as Figs. 2(d)-(f). It can be seen that platinum oxide formation is always irreversible, but the extent of its formation and the potential where it is formed varies strongly with $\mathrm{pH}$. At $\mathrm{pH} 9$, a well formed oxidation peak is seen at $\mathrm{E}_{\mathrm{p}}=+590 \mathrm{mV} v \mathrm{~s}$. SCE and the charge associated with the surface oxidation is $\approx 1.5 \mathrm{mC} \mathrm{cm}^{-2}$ suggesting a final thickness of 1-5 monolayers depending on the real microroughness of the polished microdiscs. In contrast, at pH 7 the anodic currents are much lower at all potentials considered, ie, much less platinum oxide is formed, and the voltammogram recorded between +400 $\mathrm{mV}$ and $+1000 \mathrm{mV}$ shows no peak but an increasing anodic current over most of the potential range. At $\mathrm{pH} 2$, the surface oxidation currents are decreased further. It can be seen that the voltammograms for the oxidation mirror the state of oxidation of the platinum surface and it appears that the presence of platinum oxide inhibits nitrite oxidation. At $\mathrm{pH} 9$, nitrite oxidation would not occur until a potential where the Pt is almost fully covered with the oxide and hence no oxidation is observed. At $\mathrm{pH} 7$, nitrite oxidation occurs on a surface with only a low oxide coverage but by $+1000 \mathrm{mV}$ the oxide coverage is becoming significant and starting to inhibit the nitrite oxidation. At $\mathrm{pH} 2$,
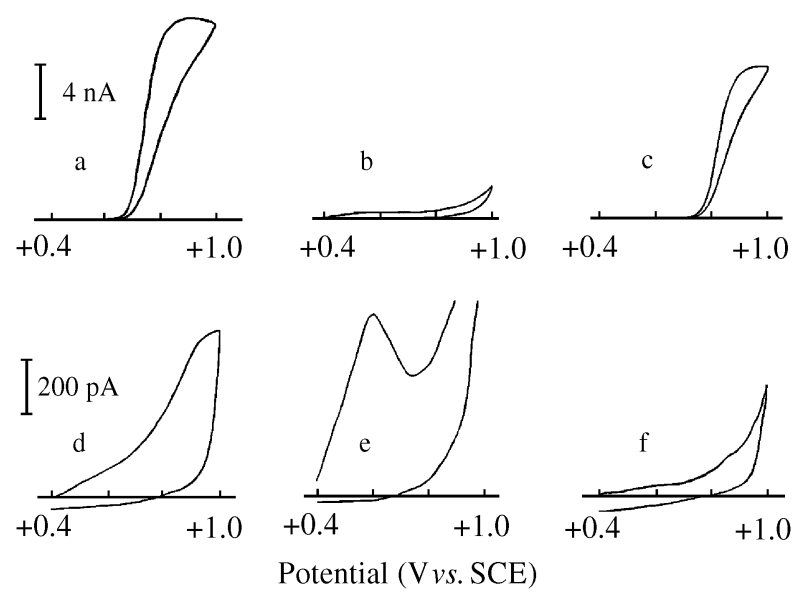

Figure 2. Cyclic voltammograms for freshly polished Pt microdisc electrodes in a solution containing $1 \mathrm{mM}$ nitrite and $0.1 \mathrm{M} \mathrm{KCl}$ (a) at $\mathrm{pH} 7$ (b) adjusted to $\mathrm{pH} 9$ by the addition of $\mathrm{KOH}$ (c) adjusted to $\mathrm{pH} 2$ by the addition of $\mathrm{H}_{2} \mathrm{SO}_{4}$. The figures (d)-(f) show the responses for the $\mathrm{Pt}$ microdisc electrode in $0.1 \mathrm{M} \mathrm{KCl}$ at the same $\mathrm{pH}$ without the addition of nitrite. Electrode radius $12.5 \mu \mathrm{m}$. Potential scan rate $20 \mathrm{mV}$ even less oxide is formed and the voltammogram for nitrite oxidation shows a better limiting current plateau and less hysterisis on the reverse scan. It was, however, noted that, in the acidic solution, the limiting current is $\approx 20 \%$ lower than that observed at $\mathrm{pH} 7$. This is not due to the decomposition of nitrite in acidic solution since the limiting current did not change with time and, if the $\mathrm{pH}$ of the acidic solution was increased back to 7 , the limiting current increased to the expected value. Presumably, the lower limiting current results from $\mathrm{n}<2$ but the chemistry in this solution has not been investigated further.

In view of the above results, it might be concluded that the electrochemical analysis is best carried out with an oxide free Pt electrode. However, attempts to determine nitrite using chronoamperometric response of a polished Pt electrode were not very successful. Although it was possible to obtain a transient where the currents had about the expected values, whatever values were chosen for the initial and measurement potentials, the I - $t$ transient was never reproducible. More importantly, repetitions without repolishing the electrode led to quite different currents. Hence, a different approach was employed.

The potential of the Pt microdisc was held at +1000 $\mathrm{mV}$ in $0.1 \mathrm{M} \mathrm{KCl}$ until the background current had reached a steady state, the electrochemical process likely being the formation of platinum oxides; this required about $400 \mathrm{~s}$ and the final current at a microdisc (radius $12.5 \mu \mathrm{m}$ ) was typically $\approx 10 \mathrm{pA}$. Aliquots of a concentrated nitrite solution were then added and the response of the microdisc noted. Figure 3 shows the results from such an experiment. During the period before the addition of nitrite, the current drops with time, initially steeply and then slowly before it asymptotes to a steady state value. After the addition of nitrite was commenced, it can be seen that the current increases linearly with nitrite concentration, see inset, and that $2 \mu \mathrm{M}$ nitrite is easily detected. In fact, the

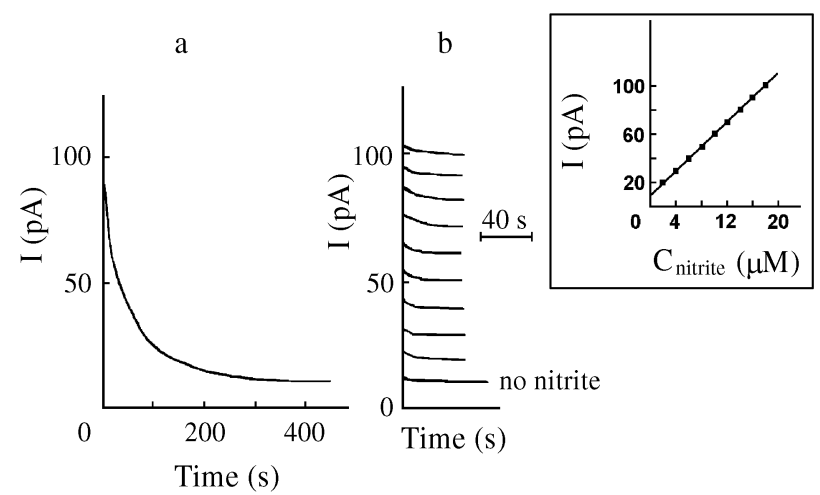

Figure 3. Current time response during (a) the pre-treatment of the freshly polished $\mathrm{Pt}$ microdisc electrode in $0.1 \mathrm{M} \mathrm{KCl}$ and (b) during the addition of aliquots of nitrite each equivalent to a solution concentration of $2 \mu \mathrm{M}$. Electrode potential $=+1000 \mathrm{mV}$. Electrode radius $12.5 \mu \mathrm{m}$. The inset shows the plot of I vs. $\mathrm{c}_{\mathrm{NO}_{2}^{-}}$. 
steady state current varies with nitrite concentration over the range $0-20 \mu \mathrm{M}$ according to the equation

$$
\mathrm{I}(\mathrm{pA})=9.5+5.2 \mathrm{c}_{\mathrm{NO}_{2}^{-}}(\mu \mathrm{M})
$$

with a regression coefficient, $r=0.99995$. Similar linear calibration plots could be obtained for nitrite concentrations up to $1 \mathrm{mM}$. Moreover, these experiments are very reproducible although the slope of this I $v$ s. c plot is only $\approx 35 \%$ of that expected for a diffusion controlled $2 \mathrm{e}^{-}$oxidation.

Figure 4 shows the results from a similar experiment but one where the oxidation of the Pt surface was carried out in $0.1 \mathrm{M} \mathrm{KCl}$ solution already containing $14 \mu \mathrm{M}$ nitrite (as would be the case for an analysis using a standard addition procedure) and further aliquots of nitrite were then added to the solution. In this case the regression line is

$$
\mathrm{I}(\mathrm{pA})=-0.4+8.3 \mathrm{c}_{\mathrm{NO}_{2}^{-}}(\mu \mathrm{M})
$$

with $r=0.9986$. The results remain reproducible but the response to nitrite is higher; the slope of the I vs. $\backslash c, N O \backslash c c o l \backslash \backslash$ plot is larger than when the Pt surface oxidation is carried out in a nitrite free solution. Uncertainties in the background current would be the limiting factor in determining the lowest detection limit. Overall, the electrode oxidised in the presence of nitrite seems to be more sensitive and this probably indicates the presence of less oxide on the surface. One explanation would be that nitrite ion, as

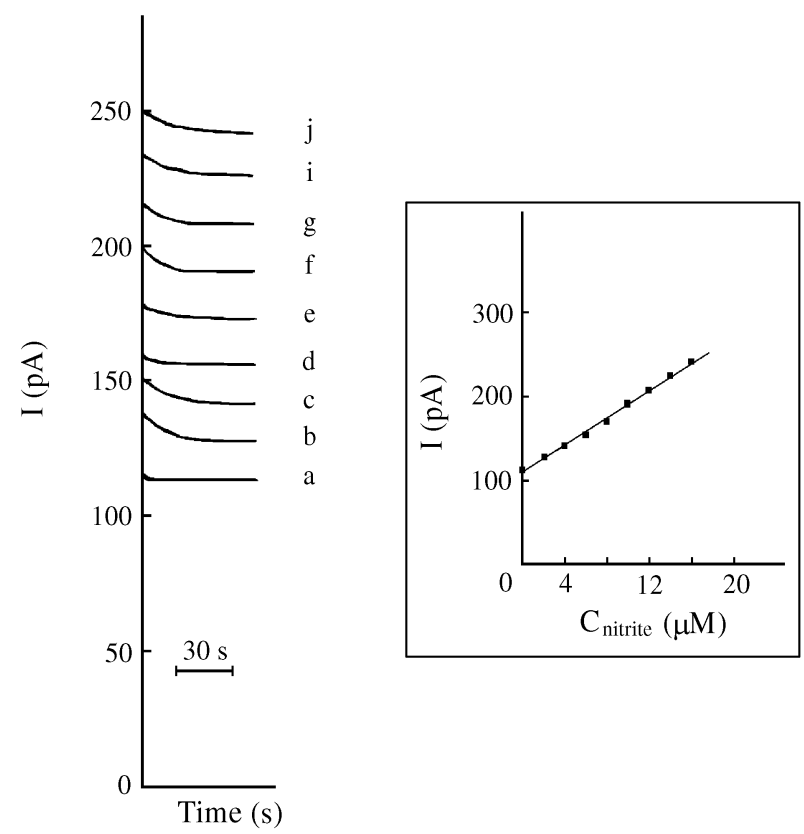

Figure 4. Current time response during the addition of nitrite each equivalent to a solution concentration of $2 \mu \mathrm{M}(\mathrm{b}-\mathrm{j})$. In this case the pre-treatment of the freshly polished Pt microdisc electrode was carried out in a $0.1 \mathrm{M} \mathrm{KCl}+14 \mu \mathrm{M}$ nitrite solution (a).Electrode potential $=+1000 \mathrm{mV}$. Electrode radius $12.5 \mu \mathrm{m}$. The inset shows the plot of I vs. $\mathbf{C}_{\text {nitrite. }}$ for example chloride, adsorbs on the Pt surface and therefore inhibits oxide formation.

\section{Discussion}

Many anode reactions in aqueous solution occur via mechanisms where an oxidised platinum species on the surface is an essential intermediate in the process. The oxidation of carbon monoxide

$$
\mathrm{CO}+\mathrm{H}_{2} \mathrm{O}-2 \mathrm{e}^{-} \longrightarrow \mathrm{CO}_{2}+2 \mathrm{H}^{+}
$$

is one example which occurs via a chemical reaction between adsorbed $\mathrm{CO}$ and surface species such as $\mathrm{Pt}-\mathrm{OH}^{17,18}$. The anodic oxidation of nitrite is clearly not this type of reaction since the formation of oxidised Pt species on the surface inhibits the reaction. This implies that nitrite oxidation occurs via a direct electron transfer mechanism, where nitrate is the final product in a $2 \mathrm{e}^{-}$reaction. This is in accordance with coulometric studies carried out at platinum electrodes by Guidelli et al. ${ }^{19}$. Based on voltammetric and potentiostatic data, the authors proposed a detailed mechanism for the anodic oxidation of nitrite which is likely to involve the formation of $\mathrm{NO}_{2}$ as a first step:

$$
\mathrm{NO}_{2}^{-}-\mathrm{e}^{-} \longrightarrow \mathrm{NO}_{2}
$$

followed by the disproprortionation reaction of $\mathrm{NO}_{2}$

$$
2 \mathrm{NO}_{2}+\mathrm{H}_{2} \mathrm{O} \longrightarrow \mathrm{NO}_{2}{ }^{-}+\mathrm{NO}_{3}{ }^{-}+2 \mathrm{H}^{+}
$$

This interpretation would certainly be compatible with the observation that the half wave potential for nitrite oxidation varies little with $\mathrm{pH}$. According to Guidelli et al. ${ }^{19}$, in the range of $\mathrm{pH}$ 3.3-7.0 the main species in solution is $\mathrm{NO}_{2}{ }^{-}$and the half wave potential is independent of $\mathrm{pH}$. However, at more acidic conditions the protonated species prevails in solution and the electrochemical reaction involves the reduction of $\mathrm{HNO}_{2}$, with a shift of $60 \mathrm{mV}$ per decade of $\mathrm{H}^{+}$concentration.

There are several known examples of simple electron transfer reactions inhibited by platinum oxide layers ${ }^{20,21}$. It is probable that the apparent catalysis of nitrite oxidation reported at some modified electrodes ${ }^{6}$ results only from a change in platinum oxide coverage; the presence of the porous polymer coating is likely to lead to a decrease in surface oxidation.

The need to pre-oxidise the Pt surface in order to obtain reproducible results lowers the sensitivity of the method but it is still possible to see a clear change in signal on addition of $2 \mu \mathrm{M}$ nitrite. Certainly, the direct oxidation at a pre-oxidised Pt microdisc provides a simple and rapid approach to nitrite analysis when it is present in concentrations in the range 5-1000 $\mu \mathrm{M}$. In practice, however, because of the relatively positive potential used for the oxidation of nitrite, it is likely that many species capable of direct anodic oxidation will be sources of potential interference. In 
such a case, the direct anodic oxidation may be preferred as a detector for flow injection methods after previous separation of the chemical species using ion chromatography. In these applications, the Pt surface is readily pre-oxidised in aqueous $0.1 \mathrm{M} \mathrm{KCl}$ in the absence of nitrite and interferences are unlikely after the chromatographic separation.

The use of a microdisc electrode adds flexibility to the electroanalysis. It allows the straightforward miniaturisation of detector cells while the signal to noise is significantly improved, thereby lowering the lowest detection limit. In addition, the application of microelectrodes would allow the determination to be made in media of low ionic strength and also reduces the dependence of the signal on the flow of the analyte past the microdisc.

\section{Acknowledgement}

The authors would like to thank the University of São Paulo for granting leave of absence to MB and FAPESP (Fundação de Amparo à Pesquisa do Estado de São Paulo) for financial support to allow MB to spend this period in Southampton.

\section{References}

1. Genders, J.D.; Hartsough, D.; Hobbs, D.T. J. Appl. Electrochem. 1996, 26, 1.

2. Kolthoff, I.M.; Harris, W.E.; Matsuyama, G. J. Am. Chem. Soc. 1944, 66, 1782.

3. van der Berg, C.M.G.; Li, H. Anal. Chim. Acta 1988, $212,31$.

4. Markusová, K Anal. Chim. Acta 1989, 221, 131.

5. Cox, J.A.; Kulesza, P.J. Anal. Chim. Acta 1984, 158, 335.
6. Cox, J.A.; Kulesza,P.J. J. Electroanal. Chem. 1984, 175, 105.

7. Cox, J.A.; Kulkarni, K.R. Analyst 1986, 111, 1219.

8. Newbery, J.E.; Lopez de Haddad, M.P. Analyst 1985 , $110,81$.

9. Chamsi, A.Y.; Fogg, A.G. Analyst 1988, 113, 1723.

10. Ultramicroelectrodes; Fleischmann, M.; Pons, S.; Rolinson, D.R.; Schmidt, P.P. Eds.; The Electrochemical Consultancy, Romsey, 1987.

11. Microelectrodes - Principles and Applications; Montenegro, M.I.; Queiros, A.M.; Daschbach, J. Eds.; NATO ASI Series, Reidel, Dordrecht, 1990.

12. Montenegro, M.I.; Geraldo, M.D.S.; Pletcher, D. Talanta 1995, 42, 1725.

13. Wightman, R.M.; Wipf, D.O. Electroanal. Chem. 1989, 15, 267.

14. Silva, S.M.; Alves, C.R.; Machado, S.A.S.; Mazo, L.; Avaca, L.A. Electroanalysis 1996, 8, 1055.

15. Standard Methods for the Examination of Water and Wastewater; Am. Public Helath Assoc., New York, 1965.

16. Self Diffusion in Electrolyte Solutions; Mills, R.; Lobo, V.M.M.; Elsevier, 1989.

17. Bilmes, S.A.; Arvia, A.J.; J. Electroanal. Chem. 1986, 198, 137.

18. Pletcher, D.; McCallum, C.J. J. Electroanal. Chem. 1976, 70, 277.

19. Guidelli, R.; Pergola, F.; Raspi, G. Anal. Chem. 1972, 44,745 .

20. Schulze, J.W.; Elfenthal, L. J. Electroanal. Chem. 1986, 204, 153.

21. Anson, F.C.; King, D.F. Anal. Chem. 1962, 34, 362. 